\title{
Gender gap in risk factor control of coronary patients far from closing: results from the European Society of Cardiology EUROASPIRE V registry
}

\author{
Pieter Vynckier $\mathbb{D}^{1}{ }^{1}$, Giulia Ferrannini ${ }^{2}$, Lars Rydén ${ }^{2}$, Piotr Jankowski ${ }^{3}$, \\ Tine De Backer (1) ${ }^{4}$, Sofie Gevaert $\mathbb{1}^{4}{ }^{4}$, Dirk De Bacquer ${ }^{1 \dagger}$, and \\ Delphine De Smedt ${ }^{1 \dagger}$; on behalf of the EUROASPIRE V Investigators group ${ }^{\ddagger}$
}

\begin{abstract}
${ }^{1}$ Department of Public Health and Primary Care, Ghent University, Corneel Heymanslaan 10, 9000 Ghent, Belgium; ${ }^{2}$ Cardiology Unit, Department of Medicine K2, Karolinska Institutet, Stockholm, Sweden; ${ }^{3}$ Department of Cardiology, Interventional Electrocardiology and Hypertension, Jagiellonian University Medical College, Kraków, Poland; and ${ }^{4}$ Department of Internal Medicine and Pediatrics, Ghent University, Ghent, Belgium
\end{abstract}

Received 23 October 2020; revised 25 November 2020; editorial decision 28 November 2020; accepted 30 November 2020

Aims

This study aims to provide an overview on contemporary gender differences in the risk factor control of coronary heart disease $(\mathrm{CHD})$ patients.

Methods

Analyses were based on the cross-sectional ESC (European Society of Cardiology) EORP (EurObservational

and results Research Programme) EUROASPIRE V (European Survey of Cardiovascular Disease Prevention and Diabetes) survey including data on CHD patients across 27 European countries. Men and women between 18 and 80 years old, hospitalized for a first or recurrent coronary event were included in the study. Data were available for 8261 patients of which $25.8 \%$ women. Overall, women had a worse risk factor control compared with men. Whereas women were more likely to be non-smokers $(79.3 \%$ vs. $87.2 \%$; $P<0.001)$, they were less likely to reach recommended levels of physical activity $(36.8 \%$ vs. $27.5 \% ; P<0.001)$, and they were less likely to be non-obese (65.1\% vs. $54.3 \% ; P<0.001)$. There is indication that risk factors such as smoking behaviour and obesity differed depending on country income level. No gender differences could be observed in blood pressure on target $(P>0.05)$. Moreover, a lower proportion of women reached low-density lipoprotein cholesterol (LDL-C) target levels (31.4\% vs. 22.1\%; $P<0.001)$, and they were less likely to reach glycated haemoglobin $(\mathrm{HbA} 1 \mathrm{c})$ targets if having self-reported diabetes $(56.7 \%$ vs. $48.6 \% ; P<0.001)$.

Conclusion $\quad$ The risk factor control of CHD women is substantial worse compared with men despite little gender differences in cardiovascular medication intake. Further actions are needed to increase the awareness of the worse risk factor control in female CHD patients.

Keywords EUROASPIRE - Gender • Risk factors - Coronary heart disease - Secondary prevention

\section{Introduction}

Cardiovascular disease (CVD) remains the leading cause of mortality and morbidity across Europe, with about $47 \%$ of women and $39 \%$ of men dying from CVD. ${ }^{1}$ In response, the European Society of Cardiology and Other Societies on Cardiovascular Disease Prevention in Clinical Practice (Joint European Societies-JES) provide regularly updated recommendations to prevent CVD by guiding

\footnotetext{
* Corresponding author. Tel: +32 9332 8335, Email: Pieter.Vynckier@Ugent.be

$\dagger$ These authors should be considered shared senior authors.

₹ All investigators are listed in Supplementary material online, Appendix S1.

Published on behalf of the European Society of Cardiology. All rights reserved. @ The Author(s) 2020. For permissions, please email: journals.permissions@oup.com.
} 
healthcare professionals in their daily clinical practice. ${ }^{1,2}$ The main objectives of these guidelines are to reduce CVD mortality and morbidity, to reduce events, and to improve patients' quality of life. ${ }^{2}$ Despite substantial efforts to promote the importance of risk factor management in patients with coronary heart disease (CHD), an unacceptably large amount of patients do not reach the recommended risk factor targets. ${ }^{3-5}$ Previous large-scale studies reporting on risk factor management suggest an even worse risk factor profile among female patients, despite gender-neutral recommendations. ${ }^{6-8}$ Women were less likely to reach adequate levels of physical activity, they were more frequently obese, and they were more likely to have a history of diabetes. ${ }^{6,8}$ Women were also less likely to reach risk factors targets for glycated haemoglobin $(\mathrm{HbA} 1 \mathrm{c})$ and low-density lipoprotein cholesterol (LDL-C). In contrast, women were more likely to be non-smokers. ${ }^{6,8}$ This gender gap in risk factor occurrence is of paramount interest, especially since risk factors like smoking and diabetes may have an even more detrimental effect in female patients. ${ }^{9,10}$ The aim of this study was to provide an overview on contemporary gender differences in risk factor control of $\mathrm{CHD}$ patients across Europe. Analyses were based on data from the latest EUROASPIRE $V$ survey. A particular focus is given to the stratification of risk factors by country income level, to investigate whether there are gender differences according to gross national income.

\section{Methods}

The cross-sectional ESC (European Society of Cardiology) EORP (EurObservational Research Programme) EUROASPIRE $\vee$ survey was conducted in 2016-2017 to evaluate the implementation of the Joint European Societies Guidelines (2016) on Cardiovascular Disease Prevention in daily clinical practice ${ }^{2}$ in coronary patients. Detailed information on the study design and methodology has been reported elsewhere. ${ }^{4}$ Within each country, at least one geographical area with a defined population was selected. A total of 131 centres were included, covering 27 countries (Belgium, Bosnia and Herzegovina, Bulgaria, Croatia, Czech Republic, Egypt, Finland, Germany, Greece, Ireland, Italy, Kazakhstan, Kyrgyzstan, Latvia, Lithuania, The Netherlands, Poland, Portugal, Romania, Russian Federation, Serbia, Slovenia, Spain, Sweden, Turkey, Ukraine, and the UK). Consecutive patients (men and women), between 18 and 80 years old at the time of identification, were retrospectively identified from diagnostic registers, hospital discharge lists, or other sources. Patients eligible for inclusion had to be hospitalized for an elective or emergency coronary artery bypass grafting (CABG), an elective or emergency percutaneous coronary intervention $(\mathrm{PCl})$, an acute myocardial infarction (AMI; ICD-10 I21), or an acute myocardial ischaemia (ICD-10 120) at least 6 months and not more than 2 years prior to the date of the study visit. Local research ethics committee approval for each participating centre was obtained. Written informed consent was completed by each participant. Data were submitted to the data management centre EURObservational Research Program (EORP), ESC, SophiaAntipolis, France. Data collection was undertaken by centrally trained research staff using standardized methods and instruments. Information on patient's demographics, risk factor profile, and disease management was obtained from medical records, patient interviews, medical examination, and venous (fasting) blood sample using standardized methods and instruments. Blood samples were centrally analysed by the Biochemistry Laboratory in the National Institute of Health and Welfare (Helsinki, Finland).

\section{Variables and definitions}

The Sixth Joint European Society guidelines (2016) were used to define the risk factor targets. ${ }^{2}$ Current smoking was defined as self-reported smoking and/or a breath carbon monoxide $>10 \mathrm{ppm}$. Smoking cessation was defined as non-smoking at time of the interview among those who smoked in the month before the recruiting event. A recommended level of physical activity was defined as regularly physical activity for at least $30 \mathrm{~min}$, five times or more a week. Obesity was defined as a body mass index $(\mathrm{BMI}) \geq 30 \mathrm{~kg} / \mathrm{m}^{2}$. Blood pressure was measured twice on the right upper arm in a sitting position using an automatic digital sphygmomanometer. The mean of both measurements was used for analyses. Targets for blood pressure were set at systolic/diastolic blood pressure (SBP/DBP) $<140 / 90 \mathrm{mmHg}(<140 / 85 \mathrm{mmHg}$ in patients with diabetes). 'Controlled hypertension' was used to indicate blood pressure levels on target in patients treated with anti-hypertensive medication. Venous (fasting) blood samples were taken to analyse LDL-C, high-density lipoprotein cholesterol (HDL-C), and HbA1c levels. The LDL-C was calculated according to the Friedewald's formula. ${ }^{11}$ Targets for LDL-C levels was defined as an LDL-C $<1.8 \mathrm{mmol} / \mathrm{L}$. 'Controlled dyslipidaemia' was used to indicate LDL-C levels on target in patients treated with lipid-lowering drugs. HbA1c level targets were defined as $<7 \%$ in patients with self-reported diabetes and $<6.5 \%$ in patients without diabetes. Previous hospitalization for stroke, heart failure, $\mathrm{CABG} / \mathrm{PCl}$, and peripheral artery disease (PAD) were defined as ever being hospitalized for a stroke, heart failure, $C A B G / P C l$, and $P A D$, respectively. Information on cardiovascular medication intake was based on medication use at the time of the study visit (patients were asked to bring their medication with them during study visit).

Educational level was divided into three categories: primary education (no formal school, less than primary school, or primary school completed), secondary education (secondary school completed, high school completed, or intermediate between secondary level), and high education (College/University completed or post-graduate degree). In addition, countries were grouped in two categories according to their gross national income per capita using the World Bank Atlas method ${ }^{12}$ : high-income countries (Belgium, Croatia, Czech Republic, Finland, Germany, Greece, Ireland, Italy, Latvia, Lithuania, Poland, Portugal, Slovenia, Spain, Sweden, The Netherlands, and UK) and middle-income countries (Bosnia and Herzegovina, Bulgaria, Egypt, Kazakhstan, Kyrgyzstan, Romania, Russian Federation, Serbia, Turkey, and Ukraine).

\section{Statistical analysis}

Descriptive statistics were used, stratified by gender, to describe patients' characteristics, the risk factor profile, and the information provided by health care professionals about patients' risk factor control. Logistic regression analyses were performed adjusted for age at interview (continuous), history of stroke, history of heart failure, and self-reported diabetes. The association between gender and the risk factor profile was expressed as odds ratios (ORs) and their $95 \%$ confidence intervals (Cls). The threshold indicating statistical significance was set at $P<0.05$. All statistical analyses were performed with IBM SPSS Statistics 25 software.

\section{Results}

\section{Patient characteristics}

Data from 8261 patients were available, of which $25.8 \%$ were women. On average, women were significantly older at the time of the study visit and had a lower educational level compared with men. Furthermore, women were more likely to have a history of stroke, 
a history of heart failure, and self-reported diabetes. Previous hospitalization for $C A B G$ or $\mathrm{PCl}$ was less frequent in women compared with men. In addition, patients recruited from middle-income countries were more often females. A detailed overview of the patient characteristics is given in Table 1.

\section{Risk factor profile}

Table 2 provides an overview of patients' risk factor profile, stratified by gender. Overall, women were significantly more likely to be nonsmokers. Also, the prevalence of smoking before the recruiting event was lower in women compared to men. No gender differences could be observed in smoking cessation. Interestingly, there is some indication that smoking behaviour differed across country income. A significant gender by country income interaction effect was found for smoking behaviour $(P<0.001)$. Stratification by country revealed a trend to significant gender differences in middle-income countries but not in high-income countries (Figure 1A). Furthermore, women were less likely to have adequate levels of physical activity. This finding was mostly consistent across countries (Figure 1B). Also, significant gender differences in disfavour of women were seen regarding the prevalence of non-obese patients. As shown in Figure 1C, gender differences in the prevalence of non-obese patients vary between countries. A significant gender by country income interaction effect was found for being non-obese $(P=0.001)$. Especially in middleincome countries, the odds of being non-obese are lower in women compared with men. Overall, no gender differences could be observed regarding blood pressure on target although gender differences varied substantially between counties (Figure 1D). Whereas no gender differences could be observed for treated hypertension (46.3\% vs. $46.6 \%$; $P=0.43$ ), women were less likely to have uncontrolled hypertension (30.0\% vs. $23.5 \% ; P=0.004)$. Interestingly, women were more likely to use anti-hypertensive medication (Table 2). Furthermore, women were less likely to have their LDL-C on target. Also, women were less likely to use lipid-lowering medication (Table 2$)$. Both for treated $(65.9 \%$ vs. $74.3 \% ; P=0.001)$ and untreated $(85.4 \%$ vs. $91.8 \%$; $P<0.001)$ patients, women were less likely to reach the LDL-C risk factor target. This pattern was quite homogeneous across countries (Figure 1E). Among patients with selfreported diabetes, women were less likely to reach the $\mathrm{HbA} 1 \mathrm{c}$ level target. No gender differences could be observed in $\mathrm{HbA} 1 \mathrm{c}$ level targets in patients without diabetes. Supplementary material online, Table S1 provides an overview of the combinations of risk factors. The combination of non-smoking, non-obese, and blood pressure on target was most common in both men and women.

\section{Discussion}

The importance of risk factor control in patients with $\mathrm{CHD}$ is widely documented. ${ }^{13-15}$ However, previous research on risk factor management reported a large proportion of CHD patients who do not reach guidelines recommended risk factor targets, especially in female patients. ${ }^{16,17}$ Overall, our study confirms previous study findings showing a worse risk factor control in female patients. Despite the fact that women smoked less, they were more likely to be physically inactive and a higher proportion of them were obese. Interestingly, no gender difference was observed in the control of blood pressure, although women used anti-hypertensive medication more often. Furthermore, LDL-C control was worse in women compared with men and women were less likely to use lipid-lowering drugs. Moreover, less women with diabetes reached the HbA1c target. Previous studies suggest that more comorbidities due to a later age of CHD onset in women and a possible lack of awareness among healthcare professionals and female patients concerning $\mathrm{CHD}$ in women resulting in delayed diagnosis, could partly explain this risk profile gender gap. ${ }^{9,18}$ Several studies reported on gender differences in the risk factor management of $\mathrm{CHD}$ patients, in disfavour of women. ${ }^{19-21}$ For instance, the VIRGO (Variation in recovery: Role of Gender on Outcomes of Young AMI Patients) study, including 3501 AMI patients, observed more diabetes and obesity in women compared with men. ${ }^{22}$ Also, the SWEDEHEART (Swedish Web System for Enhancement and Development of Evidence-Based Care in the Heart Disease Evaluated According to Recommended Therapies) registry, based on $51620 \mathrm{AMI}$ patients, reported on gender differences regarding blood pressure control and LDL-C targets, in disfavour of women. ${ }^{7}$ Moreover, the REACH Registry, based on 19105 patients with documented arterial disease, reported that women were more likely to have elevated cholesterol levels and more women were obese. ${ }^{23}$ Furthermore, the previous EUROASPIRE IV survey, conducted in 7998 coronary artery disease patients demonstrated that more women had a higher prevalence of obesity and they were less likely to have adequate levels of physical activity, LDL$\mathrm{C}$ on target, and an $\mathrm{HbA} 1 \mathrm{c}$ on target (in patients with self-reported diabetes). ${ }^{6}$ In an attempt to reduce these gender differences, several actions at the population level are taken to improve the awareness of CHD in female patients, such as 'Go Red for Women', an annual international awareness campaign initiated in 2004 to increase the awareness of CVD in women and which was endorsed by The World Heart Federation. The aim is to empower female patients to take charge of their own heart health. ${ }^{24}$ Moreover, over 50 countries are running campaigns among healthcare professionals and the general public in order to increase the awareness of CVD in women. ${ }^{24}$ Since individual behaviour is influenced by family, culture, and local policies, a population-wide strategy may be more successful in bridging the gender gap in cardiovascular disease burden. ${ }^{2}$

In continuation of previous research and the numerous awareness campaigns, the aim of this study was to provide a contemporary overview on potential gender differences in risk factor control in CHD patients, based on data from the most recent EUROASPIRE $V$ survey. Despite several actions in order to reduce the CVD burden in women, our study results largely confirm previous research, showing substantial gender differences in the risk factor control of CHD patients. The implementation of the JES guidelines on risk factor target management in secondary prevention is suboptimal, especially in women. As reported in previous studies, women in this study were more likely to be non-smokers. ${ }^{6,25}$ In this study, a remarkable gender difference was found. Analyses stratified by country revealed a trend to significant gender differences in middle-income countries but not in high-income countries. A possible explanation could be that there are increased smoking rates in female patients, especially in younger women from high-income countries. ${ }^{16}$ However, these results should be interpreted with caution because EUROASPIRE centres may be not representative for the entire country. Interestingly, no 
Table I Patient's characteristics

\begin{tabular}{|c|c|c|c|}
\hline & Men $(n=6132)$ & Women $(n=2129)$ & $P$-value \\
\hline Age, mean (SD) & $63.0(9.7)$ & $65.4(9.2)$ & $<0.001^{\mathrm{a}}$ \\
\hline Educational level, \% ( $n$ ) & & & $<0.001^{b}$ \\
\hline Primary & $13.9 \%(834)$ & $18.2 \%(383)$ & \\
\hline Secondary & $58.4 \%(3514)$ & $56.1 \%(1179)$ & \\
\hline High & $27.7 \%(1669)$ & $25.6 \%(538)$ & \\
\hline Country income level, \% (n) & & & $<0.001^{b}$ \\
\hline High & $59.8 \%(3666)$ & $53.6 \%(1142)$ & \\
\hline Middle & $40.2 \%(2466)$ & $46.4 \%(987)$ & \\
\hline \multicolumn{4}{|l|}{ Previous hospitalization, \% (n) } \\
\hline CABG & $20.4 \%(1253)$ & $13.2 \%(282)$ & $<0.001^{c}$ \\
\hline $\mathrm{PCl}$ & $82.1 \%(5035)$ & $74.9 \%(1594)$ & $<0.001^{c}$ \\
\hline Stroke & $3.7 \%(229)$ & $5.3 \%(112)$ & $0.04^{c}$ \\
\hline Heart failure & $5.9 \%(362)$ & $7.6 \%(162)$ & $0.02^{c}$ \\
\hline Peripheral artery disease & $2.7 \%(167)$ & $2.5 \%(54)$ & $0.25^{c}$ \\
\hline Self-reported diabetes & $28.0 \%(1703)$ & $33.1 \%(697)$ & $<0.001^{c}$ \\
\hline Country & & & $<0.001^{b}$ \\
\hline Belgium & $3.0 \%(183)$ & $1.8 \%(39)$ & \\
\hline Bosnia and Herzegovina & $2.6 \%(159)$ & $2.3 \%(49)$ & \\
\hline Bulgaria & $4.1 \%(249)$ & $4.9 \%(104)$ & \\
\hline Croatia & $5.0 \%(304)$ & $4.4 \%(94)$ & \\
\hline Czech Republic & $5.0 \%(306)$ & $4.7 \%(100)$ & \\
\hline Egypt & $3.9 \%(240)$ & $5.1 \%(108)$ & \\
\hline Finland & $1.9 \%(119)$ & $3.1 \%(66)$ & \\
\hline Germany & $5.2 \%(319)$ & $3.4 \%(73)$ & \\
\hline Greece & $1.5 \%(94)$ & $1.2 \%(25)$ & \\
\hline Ireland & $4.0 \%(248)$ & $2.4 \%(51)$ & \\
\hline Italy & $2.4 \%(147)$ & $1.6 \%(34)$ & \\
\hline Kazakhstan & $4.6 \%(285)$ & $6.2 \%(132)$ & \\
\hline Kyrgyzstan & $3.6 \%(219)$ & $6.5 \%(139)$ & \\
\hline Latvia & $1.6 \%(97)$ & $1.9 \%(41)$ & \\
\hline Lithuania & $4.5 \%(278)$ & $5.4 \%(116)$ & \\
\hline The Netherlands & $2.5 \%(155)$ & $1.8 \%(38)$ & \\
\hline Poland & $4.7 \%(288)$ & $5.4 \%(116)$ & \\
\hline Portugal & $3.8 \%(231)$ & $3.0 \%(64)$ & \\
\hline Romania & $4.8 \%(293)$ & $5.0 \%(106)$ & \\
\hline Russian Federation & $4.7 \%(291)$ & $5.1 \%(108)$ & \\
\hline Serbia & $4.1 \%(250)$ & $4.0 \%(85)$ & \\
\hline Slovenia & $1.7 \%(103)$ & $2.2 \%(46)$ & \\
\hline Spain & $4.5 \%(276)$ & $3.9 \%(83)$ & \\
\hline Sweden & $3.3 \%(201)$ & $2.6 \%(55)$ & \\
\hline Turkey & $3.1 \%(188)$ & $2.2 \%(46)$ & \\
\hline Ukraine & $4.8 \%(292)$ & $5.2 \%(110)$ & \\
\hline UK & $5.2 \%(317)$ & $4.8 \%(103)$ & \\
\hline
\end{tabular}

CABG, coronary artery bypass grafting; Non-STEMI; non-ST-elevation myocardial infarction; PCI, percutaneous coronary intervention; STEMI, ST-elevation myocardial infarction.

andependent samples $t$-test.

' The $\chi^{2}$ test.

'Logistic regression adjusted for age.

gender differences could be observed in smoking cessation. Moreover, women were more likely to be obese and have inadequate levels of physical activity. Also, women had a higher prevalence of self-reported diabetes and they were less likely to reach $\mathrm{HbA1c}$ level targets if having diabetes. Evidence suggests a growing burden of obesity, which may have an impact on other risk 
Table 2 Modifiable risk factors and their control at the time of interview

\begin{tabular}{|c|c|c|c|c|}
\hline All countries & Men & Women & $P$-value & $\begin{array}{l}\text { Odds ratio }(95 \% \mathrm{Cl}) \\
\text { (women vs. men) }\end{array}$ \\
\hline \multicolumn{5}{|l|}{ Smoking } \\
\hline Non-smoking & $79.3 \%(4863)$ & $87.2 \%(1857)$ & $<0.001$ & $1.57(1.36-1.82)$ \\
\hline Smoking cessation & $45.8 \%(967)$ & $43.5 \%(186)$ & 0.32 & $0.90(0.73-1.11)$ \\
\hline \multicolumn{5}{|l|}{ Physical activity } \\
\hline Recommended levels of physical activity ${ }^{a}$ & $36.8 \%(2051)$ & $27.5 \%(516)$ & $<0.001$ & $0.69(0.61-0.77)$ \\
\hline \multicolumn{5}{|l|}{ Body weight } \\
\hline Non-obese $\mathrm{e}^{\mathrm{b}}$ & $65.1 \%(3935)$ & $54.3 \%(1127)$ & $<0.001$ & $0.63(0.57-0.70)$ \\
\hline \multicolumn{5}{|l|}{ Blood pressure } \\
\hline $\mathrm{BP}$ on target ${ }^{\mathrm{c}}$ & $57.9 \%(3524)$ & $57.4 \%(1208)$ & 0.24 & $1.06(0.96-1.18)$ \\
\hline Anti-hypertensive medication & $75.7 \%(4488)$ & $83.1 \%(1722)$ & $<0.001$ & $1.44(1.26-1.64)$ \\
\hline \multicolumn{5}{|l|}{ Cholesterol } \\
\hline LDL-cholesterol on target $^{\mathrm{d}}$ & $31.4 \%(1767)$ & $22.1 \%(433)$ & $<0.001$ & $0.59(0.52-0.67)$ \\
\hline Lipid-lowering medication & $85.6 \%(5188)$ & $80.1 \%(1684)$ & $<0.001$ & $0.66(0.58-0.75)$ \\
\hline \multicolumn{5}{|l|}{$\mathrm{HbA} 1 \mathrm{C}$} \\
\hline $\mathrm{HbA} 1 \mathrm{c}<7 \%$ & $56.7 \%(918)$ & $48.6 \%(314)$ & $<0.001$ & $0.70(0.58-0.84)$ \\
\hline $\mathrm{HbA} 1 \mathrm{c}<6.5 \%{ }^{\mathrm{e}}$ & $95.3 \%$ (4007) & $95.2 \%(1285)$ & 0.75 & $0.95(0.71-1.27)$ \\
\hline
\end{tabular}

Logistic regression adjusted for sex, age, stroke, heart failure, and self-reported diabetes. These bold values were to show that the result is significant $(P<0.05)$.

BP, blood pressure; HbA1c, glycated haemoglobin; LDL-cholesterol, low-density lipoprotein.

aPhysical activity more than $30 \mathrm{~min}$ for five times/week.

${ }^{\mathrm{b}} \mathrm{BMI}<30 \mathrm{~kg} / \mathrm{m}^{2}$.

'Blood pressure $<140 / 90$ ( $<140 / 85$ if diabetes).

'LDL-cholesterol $<1.8 \mathrm{mmol} / \mathrm{L}$.

e $\mathrm{HbA} 1 \mathrm{c}<7 \%$ if having self-reported diabetes, $\mathrm{HbA} 1 \mathrm{c}<6.5 \%$ if having no self-reported diabetes.
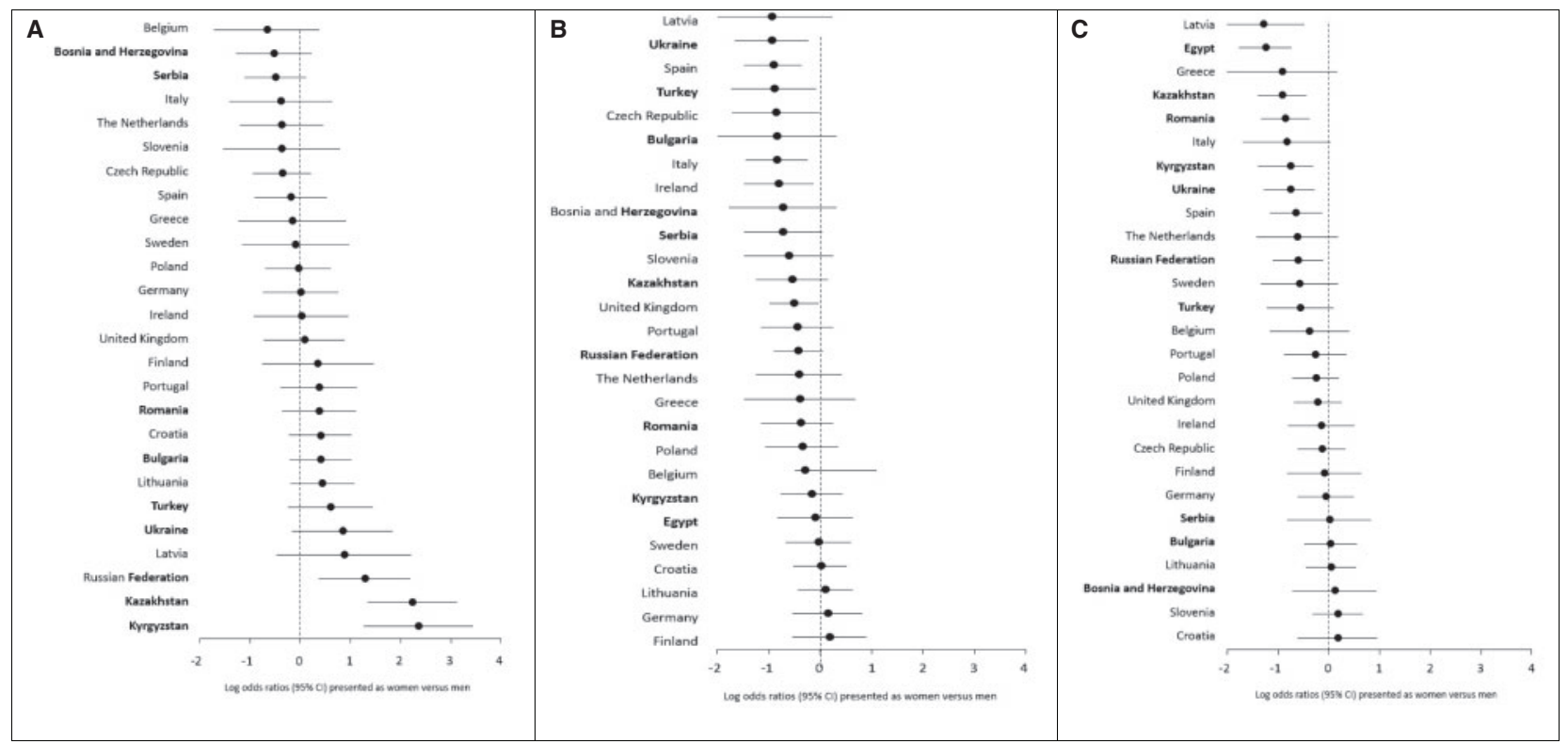

Figure I Risk factor profile. (A) Non-smoking. (B) Adequate physical activity. (C) Non-Obese ${ }^{\mathrm{a}}$. (D) Blood pressure on target ${ }^{\mathrm{b}}$. (E) Low-density lipoprotein cholesterol on target ${ }^{c}$. Logistic regression adjusted for sex, age, stroke, heart failure, and diabetes. This figure includes log odds ratios $(95 \% \mathrm{Cl})$ presented as women vs. men. Countries in bold are middle-income countries. ${ }^{\mathrm{a}} \mathrm{BMl}<30 \mathrm{~kg} / \mathrm{m}^{2}$. ${ }^{\mathrm{b}} \mathrm{Blood}$ pressure $<140 / 90(<140 / 85$ if having diabetes). ${ }^{C} \mathrm{LDL}-\mathrm{C}<1.8 \mathrm{mmol} / \mathrm{L}$. 


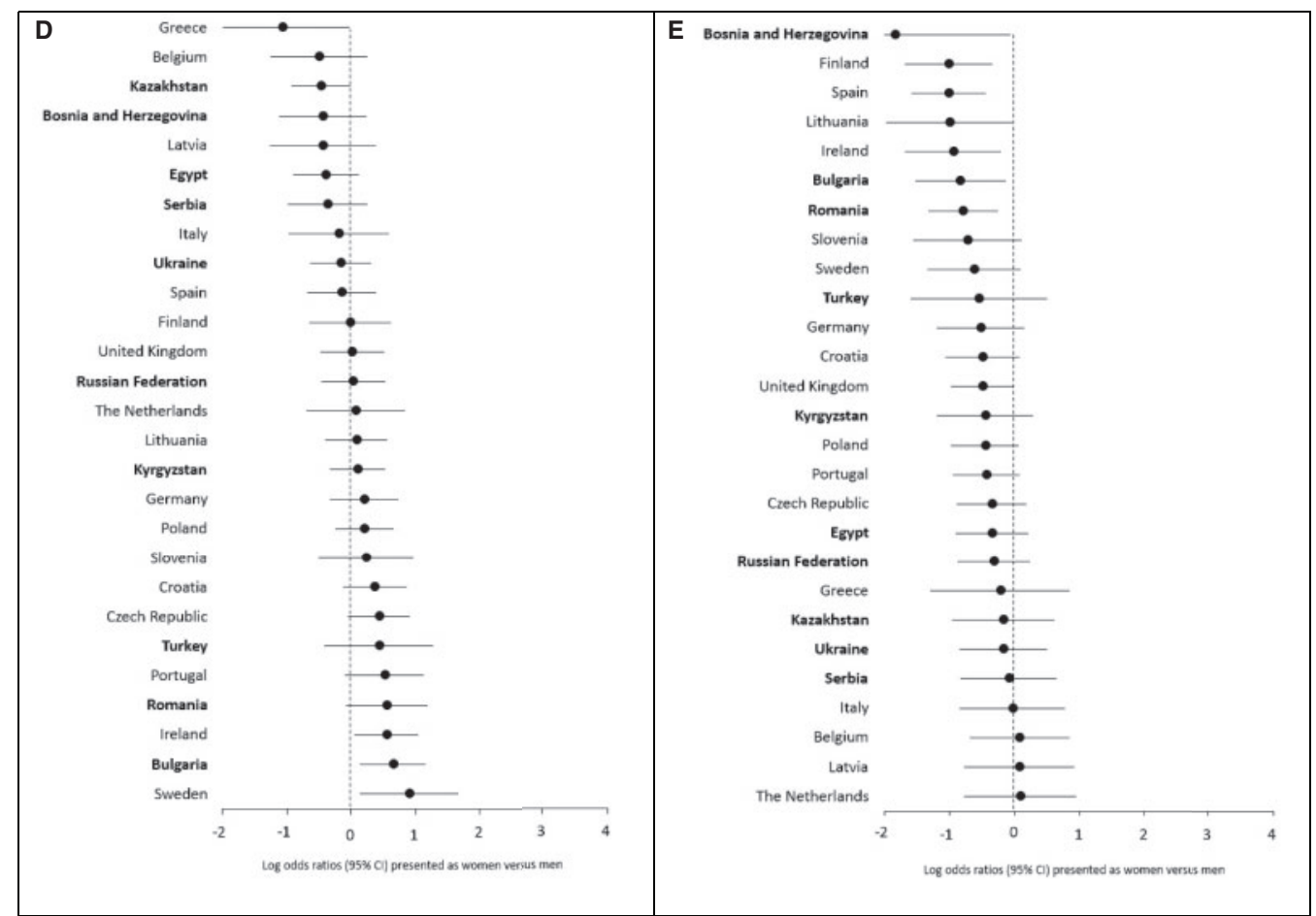

Figure I Continued.

factors, such as raised blood pressure and diabetes. ${ }^{4,26}$ It is possible that women were more likely to have diabetes due to the higher prevalence of obesity, which can partly explain these findings. Furthermore, women were less likely to reach LDL-C level targets. These findings are in line with the SURF (Survey of Risk Factors) study, based on 10112 CHD patients (2012-13). ${ }^{8}$ A possible explanation could be that there is insufficient evidence about the effectiveness of evidence-based medications in women. ${ }^{8,27}$ Evidence-based guidelines are based on large clinical trials, which are typically dominated by male participants. ${ }^{16}$ Interestingly, as shown in our study, women were less likely to use lipid-lowering medication at the time of the study visit. Previous research confirmed this findings, reporting that women were less likely to be treated with statins which can partly explain this gender difference in LDL-C control. ${ }^{7}$ Also, women are less likely to adhere to statins because of more side effects. ${ }^{28}$ Similar to previous studies (EUROASPIRE IV, the VIRGO-study) no gender differences could be observed in the overall blood pressure control. ${ }^{6,29}$ Remarkably, women were more likely than men to use antihypertensive medication at the time of the study visit.

It has to be underlined that previous EUROASPIRE analyses regarding gender differences in medical treatment revealed little to no gender differences. ${ }^{6,30}$ The risk factor profile of female patients remains suboptimal. There are several possible explanations for the worse risk factor control in female patients diagnosed with CHD. First, as suggested in the INTERHEART study, women developed $\mathrm{CHD}$ on average 10 years later compared with men. Women may therefore have a lower risk factor burden at younger age. ${ }^{31}$ This might be partly explained by the protective effect of oestrogens. ${ }^{32}$
Due to the older age of onset, women may already have a worse risk factor profile before the recruiting event, which may result in a greater effort needed to bring them on target. Further research should focus on existing gender differences in primary prevention, which can explain this gender gap. ${ }^{33,34}$ Moreover, research suggests that women were less likely to be told by a healthcare professional that they were at risk. ${ }^{22}$ In addition, women were more likely to have anxiety and depression, which were associated with a higher prevalence of risk factors like inadequate levels of physical activity and obesity. ${ }^{35,36}$ This could be a possible explanation for the lower levels of physical activity and a higher prevalence of obesity in women.

A major strength of the EUROASPIRE surveys is that data are based on standardized methods and equipment, including central laboratory analyses. Therefore, we believe the EUROASPIRE $\vee$ survey provides reliable information on the actual risk factor profile of coronary patients in Europe. Although our study provides an up to date overview on the risk factor control of CHD patients, some limitations should be mentioned. Not all geographical areas within each country were selected by the national principal investigators and may therefore not be representative for the entire country. The average EUROASPIRE $V$ interview participation rate was low (56\%). Non-participants may have a worse lifestyle and a poorer risk factor control.

\section{Conclusion}

In conclusion, although risk factor management is a major component in CHD care in both genders, our results suggest substantial gender 
differences for secondary prevention, mostly in disfavour of women. Despite the fact that previous EUROASPIRE findings suggest that there are only limited gender differences in the medical treatment of CHD patients, this was not reflected in their risk factor profile. Actions are needed to further elucidate this gender-differential in risk factor control.

\section{Supplementary material}

Supplementary material is available at European Journal of Preventive Cardiology online.

\section{Acknowledgements}

Registry Executive Committee and Steering Committee of the EURObservational Research Programme (EORP). Data collection was conducted by the EORP department from the ESC by Emanuela Fiorucci as Project Officer, Viviane Missiamenou, and Florian Larras as Data Manager. All investigators are listed in Supplementary material online, Appendix S1. The EUROASPIRE Study Group is grateful to the administrative staff, physicians, nurses and other personnel in the hospitals in which the survey was carried out and to all patients who participated in the surveys.

\section{Funding}

The EUROASPIRE $V$ survey was carried out under the auspices of the European Society of Cardiology, EURObservational Research Programme (EORP). Since the start of EORP, the following companies have supported the programme: Amarin, Amgen, Daiichi Sankyo, Elli Lily, Ferrer, Novo Nordisk, Pfizer, and Sanofi. The sponsors of the EuroAspire surveys had no role in the design, data collection, data analysis, data interpretation, decision to publish, or writing the manuscript. P.V. is financially supported by the 'Fonds voor Hartchirurgie-Fonds pour la Chirurgie Cardiaque'.

Conflict of interest: The authors declare that there is no conflict of interest.

\section{References}

1. Timmis A, Townsend N, Gale CP, Torbica A, Lettino M, Petersen SE, Mossialos EA, Maggioni AP, Kazakiewicz D, May HT, De Smedt D, Flather M, Zuhlke L, Beltrame JF, Huculeci R, Tavazzi L, Hindricks G, Bax J, Casadei B, Achenbach S, Wright L, Vardas P; European Society of Cardiology. European Society of Cardiology: cardiovascular disease statistics 2019. Eur Heart J 2020;41:12-85.

2. Piepoli MF, Hoes AW, Agewall S, Albus C, Brotons C, Catapano AL, Cooney MT, Corrà U, Cosyns B, Deaton C, Graham I, Hall MS, Hobbs FDR, Løchen M-L, Löllgen H, Marques-Vidal P, Perk J, Prescott E, Redon J, Richter DJ, Sattar N, Smulders Y, Tiberi M, van der Worp HB, van Dis I, Verschuren WMM, Binno S; ESC Scientific Document Group. 2016 European Guidelines on cardiovascular disease prevention in clinical practice: The Sixth Joint Task Force of the European Society of Cardiology and Other Societies on Cardiovascular Disease Prevention in Clinical Practice (constituted by representatives of 10 societies and by invited experts) Developed with the special contribution of the European Association for Cardiovascular Prevention \& Rehabilitation (EACPR). Eur Heart J 2016;37:2315.

3. Dallongevillle J, De Bacquer D, Heidrich J, De Backer G, Prugger C, Kotseva K, Montaye M, Amouyel P; on behalf of the EUROASPIRE Study Group. Gender differences in the implementation of cardiovascular prevention measures after an acute coronary event. Heart 2010;96:1744-1749.

4. Kotseva K, De Backer G, De Bacquer D, Rydén L, Hoes A, Grobbee D, Maggioni A, Marques-Vidal P, Jennings C, Abreu A, Aguiar C, Badariene J, Bruthans J, Castro Conde A, Cifkova R, Crowley J, Davletov K, Deckers J, De Smedt D, De Sutter J, Dilic M, Dolzhenko M, Dzerve V, Erglis A, Fras Z, Gaita D, Gotcheva N,
Heuschmann P, Hasan-Ali H, Jankowski P, Lalic N, Lehto S, Lovic D, Mancas S, Mellbin L, Milicic D, Mirrakhimov E, Oganov R, Pogosova N, Reiner Z, Stöerk S, Tokgözoğlu L, Tsioufis C, Vulic D, Wood D; on behalf of the EUROASPIRE Investigators. Lifestyle and impact on cardiovascular risk factor control in coronary patients across 27 countries: results from the European Society of Cardiology ESC-EORP EUROASPIRE V registry. Eur J Prev Cardiol 2019;26: 824-835.

5. Zhao M, Cooney MT, Klipstein-Grobusch K, Vaartjes I, De Bacquer D, De Sutter J, Reiner Ž, Prescott E, Faggiano P, Vanuzzo D, AlFaleh H, Menown IB, Gait D, Posogova N, Sheu WH-H, Zhao D, Zuo H, Grobbee DE, Graham IM. Simplifying the audit of risk factor recording and control: a report from an international study in 11 countries. Eur J Prev Cardiol 2016;23:1202-1210.

6. De Smedt D, De Bacquer D, De Sutter J, Dallongeville J, Gevaert S, De Backer G, Bruthans J, Kotseva K, Reiner Ž, Tokgözoğlu L, Clays E. The gender gap in risk factor control: effects of age and education on the control of cardiovascular risk factors in male and female coronary patients. The EUROASPIRE IV study by the European Society of Cardiology. Int J Cardiol 2016;209:284-290.

7. Hambraeus K, Tydén P, Lindahl B. Time trends and gender differences in prevention guideline adherence and outcome after myocardial infarction: data from the SWEDEHEART registry. Eur J Prev Cardiol 2016;23:340-348.

8. Zhao M, Vaartjes I, Graham I, Grobbee D, Spiering W, Klipstein-Grobusch K Woodward M, Peters SA. Sex differences in risk factor management of coronary heart disease across three regions. Heart 2017;103:1587-1594.

9. Haider A, Bengs S, Luu J, Osto E, Siller-Matula J M, Muka T, Gebhard C. Sex and gender in cardiovascular medicine: presentation and outcomes of acute coronary syndrome. European Heart Journal 2020;41:1328-1336. 10.1093/eurheartj/ehz898

10. Maas AH, Appelman YE. Gender differences in coronary heart disease. Neth Heart J 2010;18:598-603.

11. Friedewald WT, Levy RI, Fredrickson DS. Estimation of the concentration of low-density lipoprotein cholesterol in plasma, without use of the preparative ultracentrifuge. Clin Chem 1972;18:499-502.

12. The World Bank. World bank national accounts data, and OECD National Accounts data files. 2018. https://datahelpdesk.worldbank.org/knowledgebase/ topics/19280-country-classification (15 September 2020).

13. Redfern J, Briffa T, Ellis E, Freedman SB. Choice of secondary prevention improves risk factors after acute coronary syndrome: 1-year follow-up of the CHOICE (Choice of Health Options In prevention of Cardiovascular Events) randomised controlled trial. Heart 2009;95:468-475.

14. Piepoli MF, Corrà U, Adamopoulos S, Benzer W, Bjarnason-Wehrens B, Cupples M, Dendale P, Doherty P, Gaita D, Höfer S, McGee H, Mendes M, Niebauer J, Pogosova N, Garcia-Porrero E, Rauch B, Schmid JP, Giannuzzi P. Secondary prevention in the clinical management of patients with cardiovascular diseases. Core components, standards and outcome measures for referral and delivery: a policy statement from the cardiac rehabilitation section of the European Association for Cardiovascular Prevention \& Rehabilitation. Endorsed by the Committee for Practice Guidelines of the European Society of Cardiology. Eur J Prev Cardiol 2014;21:664-681

15. Piepoli MF, Abreu A, Albus C, Ambrosetti M, Brotons C, Catapano AL, Corra U, Cosyns B, Deaton C, Graham I, Hoes A, Lochen M-L, Matrone B, Redon J, Sattar N, Smulders Y, Tiberi M. Update on cardiovascular prevention in clinical practice: a position paper of the European Association of Preventive Cardiology of the European Society of Cardiology. Eur J Prev Cardiol 2020;27:181-205.

16. Maas AHEM, van der Schouw YT, Regitz-Zagrosek V, Swahn E, Appelman YE, Pasterkamp G, ten Cate H, Nilsson PM, Huisman MV, Stam HCG, Eizema K, Stramba-Badiale M. Red alert for women's heart: the urgent need for more research and knowledge on cardiovascular disease in women: proceedings of the workshop held in Brussels on gender differences in cardiovascular disease, 29 September 2010. Eur Heart J 2011;32:1362-1368.

17. Papakonstantinou NA, Stamou MI, Baikoussis NG, Goudevenos J, Apostolakis E. Sex differentiation with regard to coronary artery disease. J Cardiol 2013;62: 4-11.

18. Hilleary RS, Jabusch SM, Zheng B, Jiroutek MR, Carter CA. Gender disparities in patient education provided during patient visits with a diagnosis of coronary heart disease. Women's Health 2019;15:174550651984559.

19. Blomkalns AL, Chen AY, Hochman JS, Peterson ED, Trynosky K, Diercks DB, Brogan GX, Boden WE, Roe MT, Ohman EM, Gibler WB, Newby LK. Gender disparities in the diagnosis and treatment of non-ST-segment elevation acute coronary syndromes: large-scale observations from the CRUSADE (Can Rapid Risk Stratification of Unstable Angina Patients Suppress Adverse Outcomes With Early Implementation of the American College of Cardiology/American Heart Association Guidelines) national quality improvement initiative. J Am Coll Cardiol 2005; 45:832-837.

20. Steg PG, Greenlaw N, Tardif J-C, Tendera M, Ford I, Kääb S, Abergel H, Fox KM, Ferrari R; on behalf of the CLARIFY Registry Investigators. Women and men 
with stable coronary artery disease have similar clinical outcomes: insights from the international prospective CLARIFY registry. Eur Heart J 2012;33:2831-2840.

21. Komajda M, Cosentino F, Ferrari R, et al. Profile and treatment of chronic coronary syndromes in European Society of Cardiology member countries: the ESC EORP CICD-LT registry. Eur J Prev Cardiol 2020. doi:10.1177/20474873 20912491.

22. Leifheit-Limson EC, D'Onofrio G, Daneshvar M, Geda M, Bueno H, Spertus JA, Krumholz HM, Lichtman JH. Sex differences in cardiac risk factors, perceived risk, and health care provider discussion of risk and risk modification among young patients with acute myocardial infarction: the VIRGO study. J Am Coll Cardiol 2015;66:1949-1957.

23. Morrell J, Zeymer U, Baumgartner I, Limbourg T, Röther J, Bhatt DL, Steg PG. Differences in management and outcomes between male and female patients with atherothrombotic disease: results from the REACH Registry in Europe. Eur J Cardiovasc Prev Rehabil 2011;18:270-277.

24. World Heart Federation. Go Red for Women-The Campaign. 2007. https://www. world-heart-federation.org/programmes/go-red-women/the-campaign/?fbclid= IwAR3LdA-xUEvTvbagzimQXpn6qFGVE4h-HCHrKlpusOuxt8v8ZkaOIrH6vQ8 (15 September 2020).

25. Hemal K, Pagidipati NJ, Coles A, Dolor RJ, Mark DB, Pellikka PA, Hoffmann U, Litwin SE, Daubert MA, Shah SH, Ariani K, Bullock-Palmer RP, Martinez B, Lee $\mathrm{KL}$, Douglas PS. Sex differences in demographics, risk factors, presentation, and noninvasive testing in stable outpatients with suspected coronary artery disease: insights from the PROMISE trial. JACC Cardiovasc Imaging 2016:9:337-346.

26. Lean ME, Leslie WS, Barnes AC, Brosnahan N, Thom G, McCombie L, Peters C, Zhyzhneuskaya S, Al-Mrabeh A, Hollingsworth KG, Rodrigues AM, Rehackova L, Adamson AJ, Sniehotta FF, Mathers JC, Ross HM, Mcllvenna Y, Stefanetti R, Trenell M, Welsh P, Kean S, Ford I, McConnachie A, Sattar N, Taylor R. Primary care-led weight management for remission of type 2 diabetes (DiRECT): an open-label, cluster-randomised trial. Lancet 2018;391:541-551.

27. Shah T, Palaskas N, Ahmed A. An update on gender disparities in coronary heart disease care. Curr Atheroscler Rep 2016;18:28.
28. Goldstein KM, Zullig LL, Bastian LA, Bosworth HB. Statin adherence: does gender matter? Curr Atheroscler Rep 2016;18:63.

29. Lichtman JH, Leifheit EC, Safdar B, Bao H, Krumholz HM, Lorenze NP, Daneshvar M, Spertus JA, D'Onofrio G. Sex differences in the presentation and perception of symptoms among young patients with myocardial infarction: evidence from the VIRGO study (variation in recovery: role of gender on outcomes of young AMI patients). Circulation 2018;137:781-790.

30. Vynckier P, Ferrannini G, Rydén L, Tokgözoğlu L, Bruthans J, Kotseva K, Wood D, De Backer T, Gevaert S, De Bacquer D, De Smedt D. Medical treatment in coronary patients: is there still a gender gap? Results from European Society of Cardiology EUROASPIRE V Registry. Cardiovasc Drug Ther J 2020. doi:10.1007/ s10557-020-07095-6.

31. Anand SS, Islam S, Rosengren A, Franzosi MG, Steyn K, Yusufali AH, Keltai M, Diaz R, Rangarajan S, Yusuf S. Risk factors for myocardial infarction in women and men: insights from the INTERHEART study. Eur Heart / 2008;29:932-940.

32. Maffei S, Guiducci L, Cugusi L, Cadeddu C, Deidda M, Gallina S, Sciomer S, Gastaldelli A, Kaski J-C. Women-specific predictors of cardiovascular disease risk-new paradigms. Int J Cardiol 2019;286:190-197.

33. Driscoll A, Beauchamp A, Lyubomirsky G, Demos L, McNeil J, Tonkin A. Suboptimal management of cardiovascular risk factors in coronary heart disease patients in primary care occurs particularly in women. Internal Med J 2011;41:730-736.

34. Zhao M, Woodward M, Vaartjes I, Millett ERC, Klipstein-Grobusch K, Hyun K, Carcel C, Peters SAE. Sex differences in cardiovascular medication prescription in primary care: a systematic review and meta-analysis. J Am Heart Assoc 2020;9: e014742.

35. De Smedt D, Clays E, Annemans L, Pardaens S, Kotseva K, De Bacquer D. Selfreported health status in coronary heart disease patients: A comparison with the general population. Eur J Cardiovasc Nurs 2015;14:117-125.

36. Pogosova N, Kotseva K, De Bacquer D, von Känel R, De Smedt D, Bruthans Dolzhenko M. Psychosocial risk factors in relation to other cardiovascular risk factors in coronary heart disease: Results from the EUROASPIRE IV survey. A registry from the European Society of Cardiology. Eur J of Prev Cardiol 2017;24: $1371-1380$. 